\title{
Erratum to: Sinkholes' Detection in a Residential Area in the State of Kuwait
}

\author{
Hasan Kamal • Waleed Abdullah
}

Published online: 21 December 2012

(c) King Fahd University of Petroleum and Minerals 2012

\section{Erratum to: Arab J Sci Eng}

DOI 10.1007/s13369-012-0334-y

The original version of this article unfortunately contains mistakes. In the place of Figs. 9 and 10, Fig. 8b was erroneously duplicated.

The correct figures are shown here.

The online version of the original article can be found under doi:10.1007/s13369-012-0334-y.

H. Kamal $(\bowtie)$

Infrastructure Risk and Reliability Program, Kuwait Institute for Scientific Research, P.O. Box 24885, SAFAT 13109, Kuwait

e-mail: hkamal@kisr.edu.kw; hsnkml@gmail.com

W. Abdullah

Civil Engineering Department, College of Engineering,

Kuwait University, P. O. Box 5969, SAFAT 13109, Kuwait

e-mail: waleed.abdullah@ku.edu.kw 


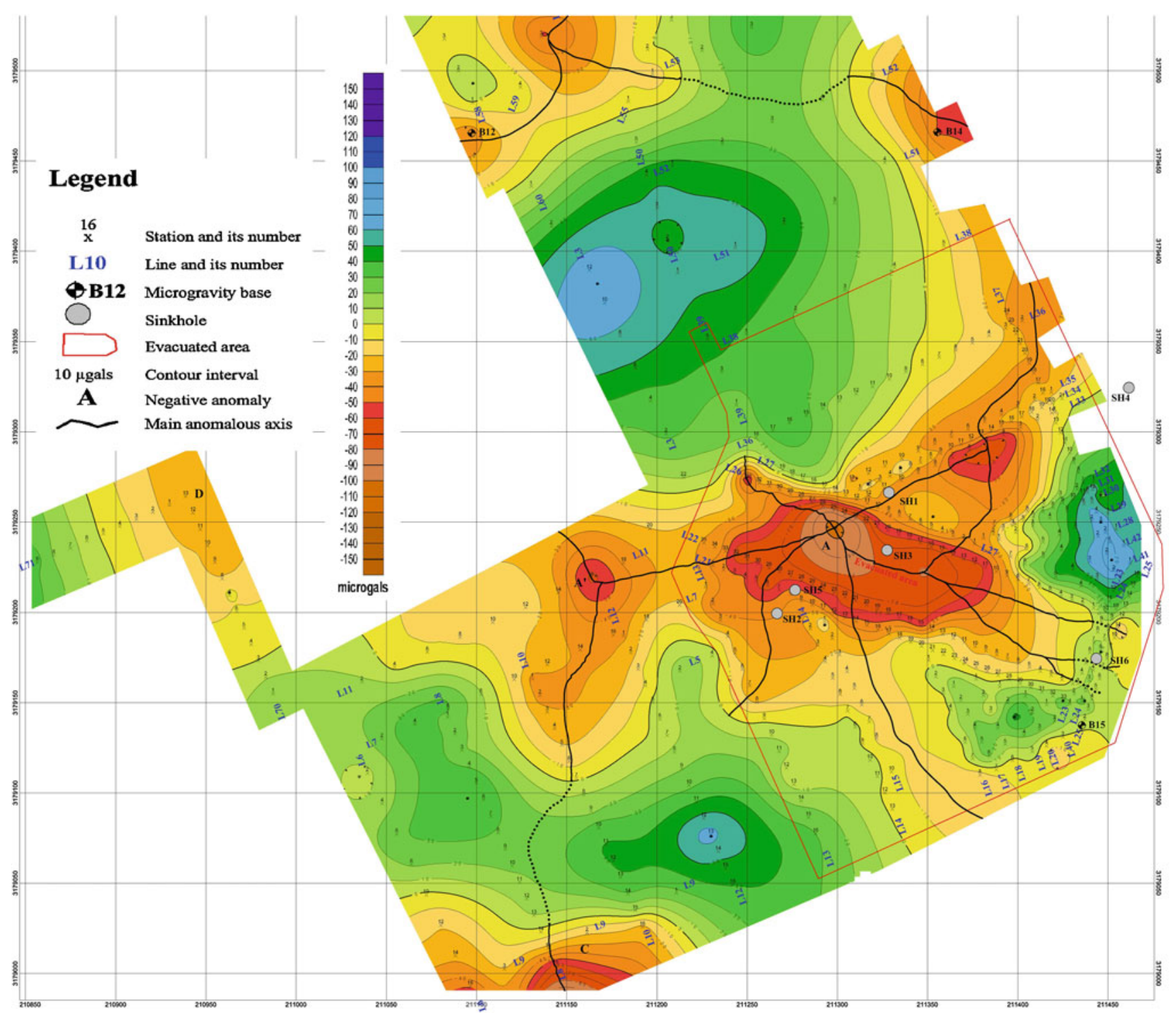

Fig. 9 Residual gravity map showing sector A1 from the 2004 survey 


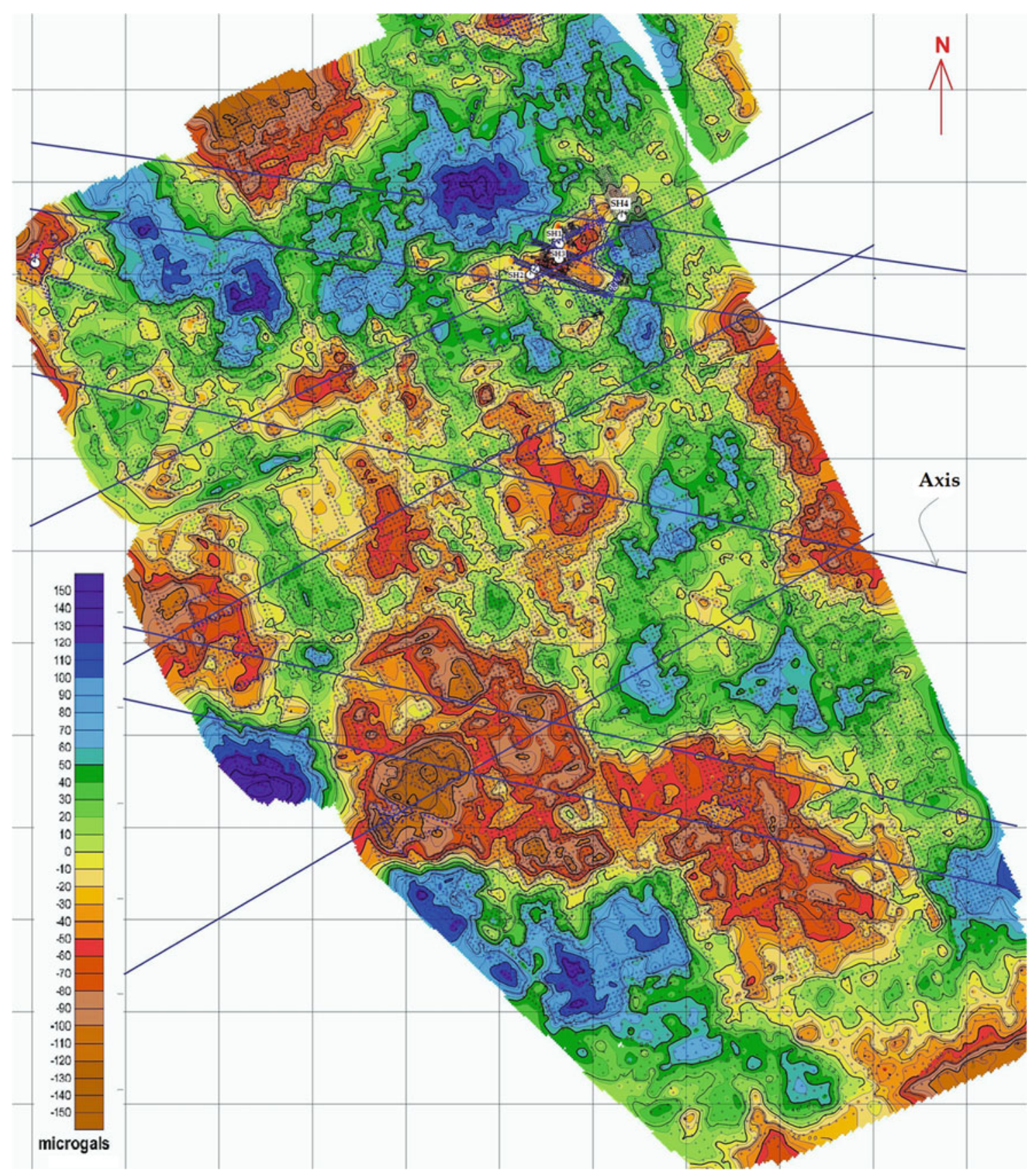

Fig. 10 Microgravity contour maps with delineation of anomalies extension trends 